\title{
A(H1N1) pandemic influenza and its prevention by vaccination: Paediatricians' opinions before and after the beginning of the vaccination campaign
}

Eve Dubé ${ }^{1,2^{*}}$, Fannie Defay ${ }^{2}$, Vladimir Gilca ${ }^{1,2}$, Julie A Bettinger ${ }^{3}$, Chantal Sauvageau ${ }^{1,2}$, France Lavoie ${ }^{2}$, François D Boucher ${ }^{2}$, Shelly McNeil ${ }^{4}$, lan Gemmill ${ }^{5}$ and Nicole Boulianne $e^{1,2}$

\begin{abstract}
Background: In June 2009, the World Health Organization declared an A(H1N1) influenza pandemic. In October 2009, the largest vaccination campaign in Canadian history began. The aim of this study was to document paediatricians' knowledge, attitudes and practices (KAP) regarding A(H1N1) pandemic influenza and its prevention by vaccination just after the beginning of the $A(H 1 N 1)$ vaccination campaign and to compare the results with those obtained before campaign initiation.
\end{abstract}

Methods: A self-administered mail-based questionnaire was sent to all Canadian paediatricians. Questionnaires were analyzed in two subsets: those received before and after the beginning of the vaccination campaign.

Results: Overall the response rate was 50\%. Respondents' characteristics were comparable between the two subsets. Before the beginning of the campaign, $63 \%$ of paediatricians perceived $\mathrm{A}(\mathrm{H} 1 \mathrm{~N} 1)$ pandemic infection as a serious disease, that would occur frequently without vaccination compared to more than $75 \%$ after. Before the vaccination campaign, half of respondents or less thought that the $\mathrm{A}(\mathrm{H} 1 \mathrm{~N} 1)$ vaccine was safe $(50 \%)$ and effective (35\%) compared to $77 \%$ and $72 \%$ after. The proportion of paediatricians who reported they had received sufficient information on $\mathrm{A}$ ( $\mathrm{H} 1 \mathrm{~N} 1$ ) vaccine increased from $31 \%$ before to $73 \%$ after the beginning of the vaccination campaign. The majority of respondents intended to get vaccinated against $\mathrm{A}(\mathrm{H} 1 \mathrm{~N} 1)$ influenza themselves ( $84 \%$ before and $92 \%$ after).

Respondents' intention to recommend the $\mathrm{A}(\mathrm{H} 1 \mathrm{~N} 1)$ vaccine to their patients increased from $80 \%$ before the beginning of the campaign to $92 \%$ after. In multivariate analysis, the main determinants of paediatricians' intention to recommend the $A(H 1 N 1)$ vaccine were their intention to get vaccinated against $A(H 1 N 1)$ influenza themselves and a belief that $A$ (H1N1) vaccine would be well accepted by health professionals who administer vaccines to the public.

Conclusion: Results of this study show important increases in physicians' level of confidence about A(H1N1) vaccine's safety and immunogenicity and their willingness to recommend this vaccine to their patients. These changes could be explained, at least partially, by the important effort done by public health authorities to disseminate information regarding $A(H 1 N 1)$ vaccination.

\section{Background}

In June 2009, the World Health Organization (WHO) declared an $\mathrm{A}(\mathrm{H} 1 \mathrm{~N} 1)$ influenza pandemic [1]. In October 2009, the largest vaccination campaign in Canadian history began. Before the start of the A(H1N1) pandemic influenza vaccination campaign, limited

\footnotetext{
* Correspondence: eve.dube@ssss.gouv.qc.ca

${ }^{1}$ Institut National de Santé publique du Québec, 2400 d’Estimauville, Québec, Canada

Full list of author information is available at the end of the article
}

information on the safety and immunogenicity of A (H1N1) influenza vaccines was available. However, the spread of $\mathrm{A}(\mathrm{H} 1 \mathrm{~N} 1)$ influenza generated intense media interest in pandemic preparedness and contradictory information around the vaccine and the vaccination campaign was reported [2-6]. During the first wave of A (H1N1) influenza in Canada, 77 deaths were reported, mostly in the provinces of Quebec and Ontario. During the second wave, in early fall 2009, 351 deaths were reported across the country [7]. In Canada, almost
() Biomed Central

C 2011 Dubé et al; licensee BioMed Central Ltd. This is an Open Access article distributed under the terms of the Creative Commons Attribution License (http://creativecommons.org/licenses/by/2.0), which permits unrestricted use, distribution, and reproduction in any medium, provided the original work is properly cited. 
exclusively, an $\mathrm{A}(\mathrm{H} 1 \mathrm{~N} 1)$ pandemic influenza vaccine (Arepanrix ${ }^{\mathrm{TM}}$ ) containing a novel adjuvant (AS03 adjuvant, as an oil-in-water emulsion) was used [8].

Physicians are known to play a key role in public acceptance of new vaccines and their recommendations are an important determinant of vaccine uptake [9-13]. Prior to the $\mathrm{A}(\mathrm{H} 1 \mathrm{~N} 1)$ vaccine approval for clinical use and the release of professional association and experts committee recommendations, we documented Canadian family physicians' and paediatricians' knowledge, attitudes and practice (KAP) regarding $\mathrm{A}(\mathrm{H} 1 \mathrm{~N} 1)$ pandemic influenza and its prevention by vaccination [14]. In this study, $59 \%$ of paediatricians had had some experience with severe cases of $\mathrm{A}(\mathrm{H} 1 \mathrm{~N} 1)$ pandemic influenza and the majority (75\%) of them were willing to recommend the $\mathrm{A}(\mathrm{H} 1 \mathrm{~N} 1)$ pandemic vaccine to their patients. More than $75 \%$ of the respondents also indicated the willingness to get the vaccine themselves [14].

The aim of this study was to document paediatricians' KAP regarding $\mathrm{A}(\mathrm{H} 1 \mathrm{~N} 1)$ pandemic influenza and its prevention by vaccination just after the beginning of the $\mathrm{A}(\mathrm{H} 1 \mathrm{~N} 1)$ vaccination campaign and to compare these results with those obtained before vaccination campaign initiation.

\section{Methods}

A self-administered, anonymous, mail-based questionnaire was sent to all Canadian paediatricians, except subspecialist. The Canadian Medical Directory [15] was used to identify paediatricians. This database contains more than 58,000 listings of Canadian physicians medical contact information and is updated each year. A multidisciplinary team developed the questionnaire using the Analytical framework for immunization programs in Canada as a theoretical base [16]. This framework was developed to guide and standardize public health decision-making process regarding new immunization programs in Canada. It includes 58 criteria classified into 13 categories. Three categories of this framework were used to guide the construction of the questionnaire: (1) Burden of disease, (2) Vaccine characteristics, and (3) Acceptability of the vaccine program. The final questionnaire included 12 questions on $\mathrm{A}$ (H1N1) pandemic influenza and its prevention by vaccination as well as 10 questions on KAP about vaccination in general and 10 questions on demographic and professional characteristics of respondents. Respondents were asked to base their answers on their own knowledge and opinions. For most questions, a 6-point Likert answer scale ranging from "strongly disagree" to "strongly agree" was used. No information on A(H1N1) pandemic influenza or the vaccines was provided. The questionnaire was mailed to 1,852 pediatricians. The first two mailings were done in August-September 2009 and the third in November 2009. The last mailing was sent to 1,118 pediatricians who had not responded to the first two mailings. The study protocol was approved by the Ethics Board of the Laval University Hospital Center (reference number 126.05.02).

All vaccines authorized for sale in Canada, including the $A(H 1 N 1)$ influenza vaccines, are reviewed and approved by the federal government (Health Canada). However, each province and territory is responsible for the development of publicly funded immunization programs, including the schedules and the logistics of administering vaccines as well as education of the population and health professionals. The $\mathrm{A}(\mathrm{H} 1 \mathrm{~N} 1)$ pandemic vaccine was approved for use in Canada on $21^{\text {st }}$ October 2009 and vaccination campaign started shortly afterwards in all Canadian provinces and territories (within days before or after $29^{\text {th }}$ October 2009). To vaccinate as many persons as possible in the shortest period of time, most Canadian jurisdictions used mass vaccination centres administered by the public system. All provincial and territorial authorities, conjointly with federal authorities, have determined a sequence of vaccination by target groups. Throughout Canada, priority to receive the $\mathrm{A}(\mathrm{H} 1 \mathrm{~N} 1)$ vaccine was given to healthcare workers. Mass vaccination campaign ended in most Canadian provinces and territories in mid-December 2009.

Due to the intense media coverage and the important educational efforts undertaken around the vaccination campaign and their potential impact on physicians' KAP $[17,18]$, we decided to perform a "before-after" analysis. Questionnaires were analyzed in two subsets: those received before (first subset) and after (second subset) the start of the vaccination campaign (October 29). Descriptive statistics were generated for all variables. Missing responses were excluded from the analyses. Univariate analyses were computed separately for the two data subsets. Comparisons of categorical responses were performed using chi-square or Fisher's exact tests. A multivariate logistic regression model was used to determine variables independently associated with the paediatrician's intention to recommend the $\mathrm{A}(\mathrm{H} 1 \mathrm{~N} 1)$ pandemic vaccine. Dependent and explanatory variables were dichotomized: the responses "strongly agree" and "agree" versus all others ("strongly disagree", "disagree", "somewhat disagree" and "somewhat agree"). Variables associated in the univariate analysis with the intention to recommend the vaccine at $\mathrm{p} \leq 0.20$ were entered into the multivariate regression models using the stepwise selection technique. The model was adjusted to take into consideration the two subsets of data. A new binary explanatory variable was created (subsequently referred to as "subset variable") and forced into the model: questionnaires mailed before the beginning of the vaccination campaign and questionnaires mailed after. Variables 
were reevaluated in the final model to check for confounding and model fit. A probability level of $\mathrm{p}<0.05$ based on two-sided tests was considered statistically significant. The collinearity was checked and the adequacy of the model was evaluated by Hosmer and Lemeshow's goodness of fit test.

Multiple correspondence analysis (MCA) method [19] was also used as a complementary way to analyse our dataset. MCA is used to detect links between variables (including, in this study, the intention to recommend the $\mathrm{A}(\mathrm{H} 1 \mathrm{~N} 1)$ vaccine), but there is no dependent variable. This method is a form of principal components analysis that is appropriate for qualitative variables. MCA searches for principal components, which are new quantitative modelled variables, constructed as linear functions of the initial variables. Finding the principal components is based on the maximisation of the correlation ratio between the principal component and the initial variables. All principal components are mutually uncorrelated by construction. Our initial variables were all variables in the questionnaire pertaining to $\mathrm{A}(\mathrm{H} 1 \mathrm{~N} 1)$ vaccine and $\mathrm{A}(\mathrm{H} 1 \mathrm{~N} 1)$ influenza and the subset variable. Analysis was computed using the raw variables (6 degrees of answers ranging from "Strongly agree" to "Strongly disagree"). We carried out this MCA as a sensitivity analysis to better assess the role of the subset variable and the impact of all 6 degrees of possible answers on the Likert scale. The Statistical Analysis Systems $\left(\mathrm{SAS}^{\mathbb{R}}\right)$ software (version 9.2 of the SAS system for Windows. Copyright (c) 2002-2008 by SAS Institute Inc., Cary, NC, USA) and R software (version 2.11.1) [20] with the library FactoMineR [21] were used for data analyses.

\section{Results}

\section{Participation and socio-professionals characteristics}

Overall, 912 paediatricians have completed the questionnaires: 714 completed the questionnaire before the beginning of the $\mathrm{A}(\mathrm{H} 1 \mathrm{~N} 1)$ vaccination campaign and 197 completed it after. After exclusion of physicians no longer practicing, those with incorrect addresses or those who were subspecialists, the overall participation rate was 50\% (911/1832). Participation rates by country regions varied from $40.1 \%$ in Prairies to $57.7 \%$ in Quebec. Table 1 shows respondents' socio-professionals characteristics. No statistically significant differences were found among the characteristics of paediatricians who complete the survey before and after the beginning of $\mathrm{A}(\mathrm{H} 1 \mathrm{~N} 1)$ vaccination campaign.

\section{Knowledge, attitudes and practices regarding vaccination in general}

Overall, $98 \%$ of paediatricians thought that vaccines recommended by public health authorities are very useful (97,6\% before and 98,5\% after; p = 0,5911), and $73 \%$ agreed or strongly agreed with the statement "it is very useful to protect children with the vaccines against seasonal influenza" (72,9\% before and 73,9\% after; $\mathrm{p}=$ $0,7855)$. When recommending new vaccines to their patients, 91\% of paediatricians indicated that they are highly influenced by expert group recommendations $(91,3 \%$ before and $90,7 \%$ after; $\mathrm{p}=0,8152)$ and $90 \%$, by professional association recommendations (90,8\% before and $89,7 \%$ after; $\mathrm{p}=0,6414)$. Approximately half of paediatricians $(49 \%)$ stated that it is easy for them to advise their patients on new vaccines. No statistically significant differences were found in attitudes towards vaccination in general between respondents who answered before or after the beginning of $\mathrm{A}(\mathrm{H} 1 \mathrm{~N} 1)$ vaccination campaign

\section{Knowledge, attitudes and practices regarding $\mathrm{A}(\mathrm{H} 1 \mathrm{~N} 1)$ pandemic influenza and its prevention by vaccination} Before the beginning of the campaign, $63 \%$ of paediatricians perceived $\mathrm{A}(\mathrm{H} 1 \mathrm{~N} 1)$ pandemic infection as a serious disease, that would occur frequently without vaccination comparatively to more than $75 \%$ after campaign initiation. In addition, less respondents considered that $\mathrm{A}(\mathrm{H} 1 \mathrm{~N} 1)$ pandemic influenza was severe enough to take special precautions to prevent it before, than after the start of the vaccination campaign $(73 \%$ agreed or strongly agreed before compared to $63 \%$ after, $\mathrm{p}=$ 0.0136) (Table 2). Before the vaccination campaign, half of respondents or less agreed or strongly agreed that the $\mathrm{A}(\mathrm{H} 1 \mathrm{~N} 1)$ vaccine was safe $(50 \%)$ and effective $(35 \%)$ compared to $77 \%$ and $72 \%$ after the start of the campaign who felt the vaccine was safe and effective ( $\mathrm{p}<$ 0.001) (Table 2). Paediatricians' perceived acceptability of $\mathrm{A}(\mathrm{H} 1 \mathrm{~N} 1)$ vaccine by the public remained comparable (45\% before versus $41 \%$ after agreed and strongly agreed, $\mathrm{p}=0.3608$ ). Paediatricians' perceived acceptability of the $\mathrm{A}(\mathrm{H} 1 \mathrm{~N} 1)$ vaccine by health professionals who administered vaccines (hereafter named "vaccine providers") increased after the beginning of vaccination campaign (71\% before versus $84 \%$ after, $\mathrm{p}<0.001$ ). Respondents' intention to recommend the $\mathrm{A}(\mathrm{H} 1 \mathrm{~N} 1)$ vaccine increased from $80 \%$ before the beginning of the campaign to $92 \%$ after, including $46 \%$ and $62 \%$ of paediatricians that declared they would strongly recommend it, respectively. Globally, $40 \%$ of respondents who disagreed with the usefulness to protect children with the seasonal influenza vaccine did not intended to recommend $\mathrm{A}(\mathrm{H} 1 \mathrm{~N} 1)$ pandemic vaccine to their patients while $2 \%$ of physicians who agreed with the usefulness of the seasonal influenza vaccine did not intended to recommend the A (H1N1) pandemic vaccine ( $\mathrm{p}<0.001)$ (data not shown). The majority of respondents intended to get vaccinated against $\mathrm{A}(\mathrm{H} 1 \mathrm{~N} 1)$ pandemic influenza themselves $(84 \%$ 
Table 1 Paediatricians' professional and demographic characteristics (\%)

\begin{tabular}{|c|c|c|c|}
\hline Characteristics & Before $N=714$ & After $N=197$ & P-value \\
\hline \multicolumn{4}{|l|}{ Sex } \\
\hline Male & 41.9 & 46.7 & 0.2327 \\
\hline \multicolumn{4}{|l|}{ Location of main practice } \\
\hline Private office & 44.6 & 42.3 & \\
\hline Hospital & 51.8 & 52.1 & 0.4371 \\
\hline Other & 3.7 & 5.7 & \\
\hline \multicolumn{4}{|c|}{ Number of hours in outpatient consultation } \\
\hline$<7$ hours & 16.7 & 24.9 & '>21 hrs' vs. others \\
\hline From 7 to 21 hours & 28.8 & 26.5 & \\
\hline$>21$ hours & 54.5 & 48.6 & 0.1571 \\
\hline \multicolumn{4}{|c|}{$\begin{array}{l}\text { Number of doses of vaccines administered each month in respondents' main } \\
\text { practice place }\end{array}$} \\
\hline None & 42.1 & 48.9 & \\
\hline$<30$ doses & 29.5 & 30.9 & $\begin{array}{l}\text { None vs. Others: } \\
\quad 0.0924\end{array}$ \\
\hline From 30 to 100 doses & 13.1 & 6.4 & \\
\hline$>100$ doses & 15.3 & 13.8 & \\
\hline \multicolumn{4}{|l|}{ Number of years of practice } \\
\hline$>20$ years & 39.6 & 37.9 & \\
\hline From 10 to 20 years & 37.2 & 40.5 & 0.6915 \\
\hline$<10$ years & 23.2 & 21.6 & \\
\hline \multicolumn{4}{|l|}{ Provinces of practice } \\
\hline Atlantic & 9 & 7.2 & \\
\hline Quebec & 29.6 & 22.2 & \\
\hline Ontario & 35.1 & 40.7 & 0.2067 \\
\hline Prairies & 16.2 & 17.5 & \\
\hline British Columbia & 10.1 & 12.4 & \\
\hline \multicolumn{4}{|c|}{ I am planning to get vaccinated against $A(H 1 N 1)$ pandemic influenza } \\
\hline Yes & 83.9 & 92.3 & 0.0028 \\
\hline No - don't know & 16.2 & 7.7 & \\
\hline
\end{tabular}

before and $92 \%$ after, $\mathrm{p}=0.003$, Table 1 ). No statistically significant differences were observed in intention to be vaccinated between paediatricians practicing in different Canadian regions, neither before $(\mathrm{p}=0.4315)$ nor after $(\mathrm{p}=0.4291)$ the beginning of the campaign. Before the beginning of the vaccination campaign, $13 \%$ of paediatricians were undecided about being vaccinated themselves compared to 3\% after. Finally, the proportion of paediatricians who reported they had received sufficient information on $\mathrm{A}(\mathrm{H} 1 \mathrm{~N} 1)$ vaccine increased from $31 \%$ before the beginning of the campaign to $73 \%$ after $(\mathrm{p}<0.001)$, with $3 \%$ of respondents reporting they felt their knowledge was insufficient after the beginning of the vaccination campaign versus $17 \%$ before (Table 2 ).

Factors associated with the intention to recommend $A$ (H1N1) pandemic vaccine before and after the start of the vaccination campaign

The intention to get vaccinated against $\mathrm{A}(\mathrm{H} 1 \mathrm{~N} 1)$ pandemic influenza themselves $(\mathrm{OR}=8.65)$ and belief that
A(H1N1) pandemic vaccine would be well accepted by vaccine providers $(\mathrm{OR}=6.65)$ were the most significant factors associated with the intention to recommend $\mathrm{A}$ (H1N1) pandemic vaccine to patients. Six other variables were also significantly associated with the intention to recommend the vaccine: belief that seasonal influenza vaccines are very useful to protect child health; perceived economic burden of $\mathrm{A}(\mathrm{H} 1 \mathrm{~N} 1)$ influenza illness; self-estimated sufficiency of knowledge about the $\mathrm{A}(\mathrm{H} 1 \mathrm{~N} 1)$ vaccine; perceived safety of the $\mathrm{A}(\mathrm{H} 1 \mathrm{~N} 1)$ vaccine; perceived severity of $\mathrm{A}(\mathrm{H} 1 \mathrm{~N} 1)$ pandemic influenza and belief that special precautions to prevent $\mathrm{A}(\mathrm{H} 1 \mathrm{~N} 1)$ pandemic influenza are needed (Table 3).

Multiple correspondence analyses (MCA)

Results of MCA supported the associations found in the logistic regression models (Figure 1). Overall, first and second principal components summarized $13.6 \%$ of the initial variables' variability. The coefficients of determination $\left(\mathrm{r}^{2}\right)$ for the first and second principal components 
Table 2 Paediatricians' knowledge, attitudes and practices regarding $A(H 1 N 1)$ pandemic influenza and vaccine (\%)

\begin{tabular}{|c|c|c|}
\hline & $\begin{array}{l}\text { Before } A(H 1 N 1) \text { vaccination } \\
\text { campaign }\end{array}$ & $\begin{array}{l}\text { After } A(\mathrm{H} 1 \mathrm{~N} 1) \text { vaccination } \\
\text { campaign }\end{array}$ \\
\hline \multicolumn{3}{|l|}{ A(H1N1) pandemic influenza... } \\
\hline Is severe enough to take special precautions to prevent it & $n=704$ & $n=195$ \\
\hline Somewhat agree & 26.6 & 20.5 \\
\hline Agree & 38.8 & 38 \\
\hline Strongly agree & 24.3 & 34.9 \\
\hline Is a serious disease ${ }^{*}$ & $n=671$ & $n=193$ \\
\hline Somewhat agree & 28,2 & 16.6 \\
\hline Agree & 37.7 & 43 \\
\hline Strongly agree & 25 & 36.3 \\
\hline Would occur frequently in Canada without vaccination * & $n=672$ & $n=190$ \\
\hline Somewhat agree & 25 & 14.2 \\
\hline Agree & 36.9 & 36.8 \\
\hline Strongly agree & 25.3 & 39 \\
\hline Generates a significant economic burden in Canada & $n=682$ & $n=190$ \\
\hline Somewhat agree & 15.3 & 9.5 \\
\hline Agree & 33.3 & 34.2 \\
\hline Strongly agree & 46.6 & 51.1 \\
\hline $\begin{array}{l}\text { In my medical practice or in my private life, I have had } \\
\text { experience with severe } \mathrm{A}(\mathrm{H} 1 \mathrm{~N} 1) \text { pandemic influenza }\end{array}$ & $n=698$ & $n=193$ \\
\hline Yes & 59 & 81.3 \\
\hline \multicolumn{3}{|l|}{$A(H 1 N 1)$ pandemic influenza vaccines will be/are... } \\
\hline Safe * & $n=615$ & $n=186$ \\
\hline Somewhat agree & 42 & 20.4 \\
\hline Agree & 34.3 & 45.7 \\
\hline Strongly agree & 15.5 & 31.7 \\
\hline Effective * & $n=590$ & $n=187$ \\
\hline Somewhat agree & 54.6 & 25.1 \\
\hline Agree & 27.1 & 43.9 \\
\hline Strongly agree & 7.5 & 28.3 \\
\hline Well accepted by the public & $n=677$ & $\mathrm{n}=187$ \\
\hline Somewhat agree & 35.9 & 41.2 \\
\hline Agree & 29.4 & 34.2 \\
\hline Strongly agree & 15.1 & 6.4 \\
\hline Well accepted by vaccine providers * & $n=671$ & $n=188$ \\
\hline Somewhat agree & 22.8 & 12.2 \\
\hline Agree & 39.5 & 46.8 \\
\hline Strongly agree & 31.7 & 37.2 \\
\hline $\begin{array}{l}\text { I consider that my knowledge on the pandemic influenza ( } \mathrm{H} 1 \mathrm{~N} 1 \text { ) vaccine is } \\
\text { sufficient * }\end{array}$ & $n=690$ & $n=193$ \\
\hline Somewhat agree & 31 & 19.2 \\
\hline Agree & 21 & 37.3 \\
\hline Strongly agree & 10.4 & 35.2 \\
\hline I will recommend the $\mathrm{A}(\mathrm{H} 1 \mathrm{~N} 1)$ pandemic vaccine to my patients* & $n=671$ & $n=189$ \\
\hline Somewhat agree & 15.7 & 5.8 \\
\hline Agree & 33.8 & 29.1 \\
\hline Strongly agree & 46.1 & 62.4 \\
\hline
\end{tabular}

* Before/after differences statistically significant at $p<0.05$. 
Table 3 Variables associated with respondents intention to recommend $A(H 1 N 1)$ pandemic vaccine in multivariate regression analysis $(\mathrm{N}=709)$ *

\begin{tabular}{|c|c|c|c|}
\hline Variables & $\begin{array}{l}\text { Adjusted } \\
\text { OR }\end{array}$ & $95 \% \mathrm{Cl}$ & $\begin{array}{c}P \\
\text { value }\end{array}$ \\
\hline $\begin{array}{l}\text { Paediatricians' intention to receive } A \\
(\mathrm{H} 1 \mathrm{~N} 1) \text { themselves }\end{array}$ & 8.65 & $4.27-17.14$ & $<0.0001$ \\
\hline $\begin{array}{l}\text { Belief }^{\S} \text { that } A(H 1 N 1) \text { vaccine will be } \\
\text { well accepted by vaccine providers }\end{array}$ & 6.60 & $3.70-11.76$ & $<0.0001$ \\
\hline $\begin{array}{l}\text { Belief }^{\S} \text { that seasonal influenza } \\
\text { vaccines are very useful to protect } \\
\text { children health }\end{array}$ & 2.84 & $1.58-5.10$ & 0.0005 \\
\hline $\begin{array}{l}\text { Belief }^{\S} \text { that } \mathrm{A}(\mathrm{H} 1 \mathrm{~N} 1) \text { pandemic } \\
\text { influenza generate a significant } \\
\text { economic burden in Canada }\end{array}$ & 2.78 & $1.51-5.08$ & 0.0010 \\
\hline $\begin{array}{l}\text { Self-estimated sufficiency of } \\
\text { knowledge on } \mathrm{A}(\mathrm{H} 1 \mathrm{~N} 1) \text { vaccine }\end{array}$ & 2.10 & $1.05-4.20$ & 0.0351 \\
\hline $\begin{array}{l}\text { Belief }^{\S} \text { that } A(H 1 N 1) \text { vaccine will be } \\
\text { safe }\end{array}$ & 2.10 & $1.13-3.90$ & 0.0195 \\
\hline $\begin{array}{l}\text { Belief }^{\S} \text { that } \mathrm{A}(\mathrm{H} 1 \mathrm{~N} 1) \text { pandemic } \\
\text { influenza is a serious disease }\end{array}$ & 2.09 & $1.13-3.88$ & 0.0189 \\
\hline $\begin{array}{l}\text { Belief }^{\S} \text { that } \mathrm{A}(\mathrm{H} 1 \mathrm{~N} 1) \text { pandemic } \\
\text { influenza is a severe enough to take } \\
\text { special precautions to prevent it }\end{array}$ & 1.88 & $1.04-3.42$ & 0.0377 \\
\hline Subset variable (before $=1$, after $=0$ ) & 0.84 & $0.36-1.96$ & 0.6864 \\
\hline
\end{tabular}

were low (maximum at 0.71 for the first principal components, and 0.57 for the second principal component). It showed that responses were homogeneous among respondents. More precisely, results showed that we could group our respondents by negative levels rather than positive levels of their answers: the levels "strongly disagree" and "disagree" were the most discriminatory levels.

Before and after the onset of the vaccination campaign, the modelled principal component had the respondents' intention to recommend $\mathrm{A}(\mathrm{H} 1 \mathrm{~N} 1)$ pandemic vaccine as principal contributor (weight for the "strongly disagree" level: 4.14). Then we found respondent's intention to receive $\mathrm{A}(\mathrm{H} 1 \mathrm{~N} 1)$ pandemic vaccine (weight for the 'no' level: 3.45), and "belief that seasonal influenza vaccines are very useful to protect children health" (weight for the "strongly disagree" level: 3.44). Mean of weight for all other variables is 0.87 , including the subset variable which was the less correlated variable (variable $\mathrm{S}$ on figure 1) with first and second principal components.

\section{Discussion}

To our knowledge, this is the first study that measured changes in physicians' KAP regarding $\mathrm{A}(\mathrm{H} 1 \mathrm{~N} 1)$ pandemic influenza and its prevention by vaccination before and after the approval of the vaccine and start of the vaccination campaign. Previous studies among health care workers assessed acceptability of the $\mathrm{A}(\mathrm{H} 1 \mathrm{~N} 1)$ vaccine before its official approval and program implementation or used hypothetical pandemic vaccination scenarios [18,22-26]. In these studies, intention to be vaccinated against $A(\mathrm{H} 1 \mathrm{~N} 1)$ pandemic influenza varied from $48 \%$ to $80 \%$ among healthcare workers, comparatively to $84 \%$ of paediatricians surveyed before the beginning of the vaccination campaign in our study. Similarly to our results, a study done in Mexico reported that $72 \%$ of healthcare workers would recommend the vaccine to their patients, and they were more likely to do so when they had the intention to get vaccinated themselves [25].

Results of this national survey among paediatricians indicated an important increase in paediatricians perceptions of the burden of $\mathrm{A}(\mathrm{H} 1 \mathrm{~N} 1)$ pandemic influenza and support for $\mathrm{A}(\mathrm{H} 1 \mathrm{~N} 1)$ vaccination after the beginning of the vaccination campaign. Respondents' endorsement of almost all items regarding $\mathrm{A}(\mathrm{H} 1 \mathrm{~N} 1)$ pandemic influenza and its prevention by vaccination increased after the start of the vaccination campaign. This is not surprising given the fact that the first $\mathrm{A}(\mathrm{H} 1 \mathrm{~N} 1)$ vaccine available in Canada used a novel adjuvant (AS03) for which limited information regarding the safety and immunogenicity was available. The proportion of physicians who reported they had received sufficient information about $\mathrm{A}(\mathrm{H} 1 \mathrm{~N} 1)$ vaccine also increased by $42 \%$ after the start of the vaccination campaign. This increase may be attributable to the important educational efforts done at the beginning of the vaccination campaign along with the official recommendations by expert groups and professional associations that were released in early November [27-29].

Health professionals' knowledge about vaccines has been previously shown as a main determinant associated with their own vaccine uptake and their intention to recommend the vaccine to their patients $[30,31]$. The association between physicians own vaccination behaviours and their recommendations to their patients was previously established [12,32-35]. It appears to hold true in a pandemic context, as shown by our results and those previously reported in Mexico [25].

Our results highlight the positive change in paediatricians' knowledge and level of support of the $\mathrm{A}(\mathrm{H} 1 \mathrm{~N} 1)$ vaccines throughout the pandemic vaccination campaign. This change may be attributable to increased education efforts and the very rare vaccine associated adverse events [36], but may also reflect the intense media attention focused on the vaccination campaign. A recent UK study has shown that healthcare workers were more willing to accept stockpiled $\mathrm{H} 5 \mathrm{~N} 1$ vaccine during a period of high media coverage of a $\mathrm{H} 5 \mathrm{~N} 1$ outbreak in a poultry farm than 6 months after $(63.4 \%$ vs. $51.9 \%, \mathrm{p}=0.009$ ) [18]. The increased exposure of 


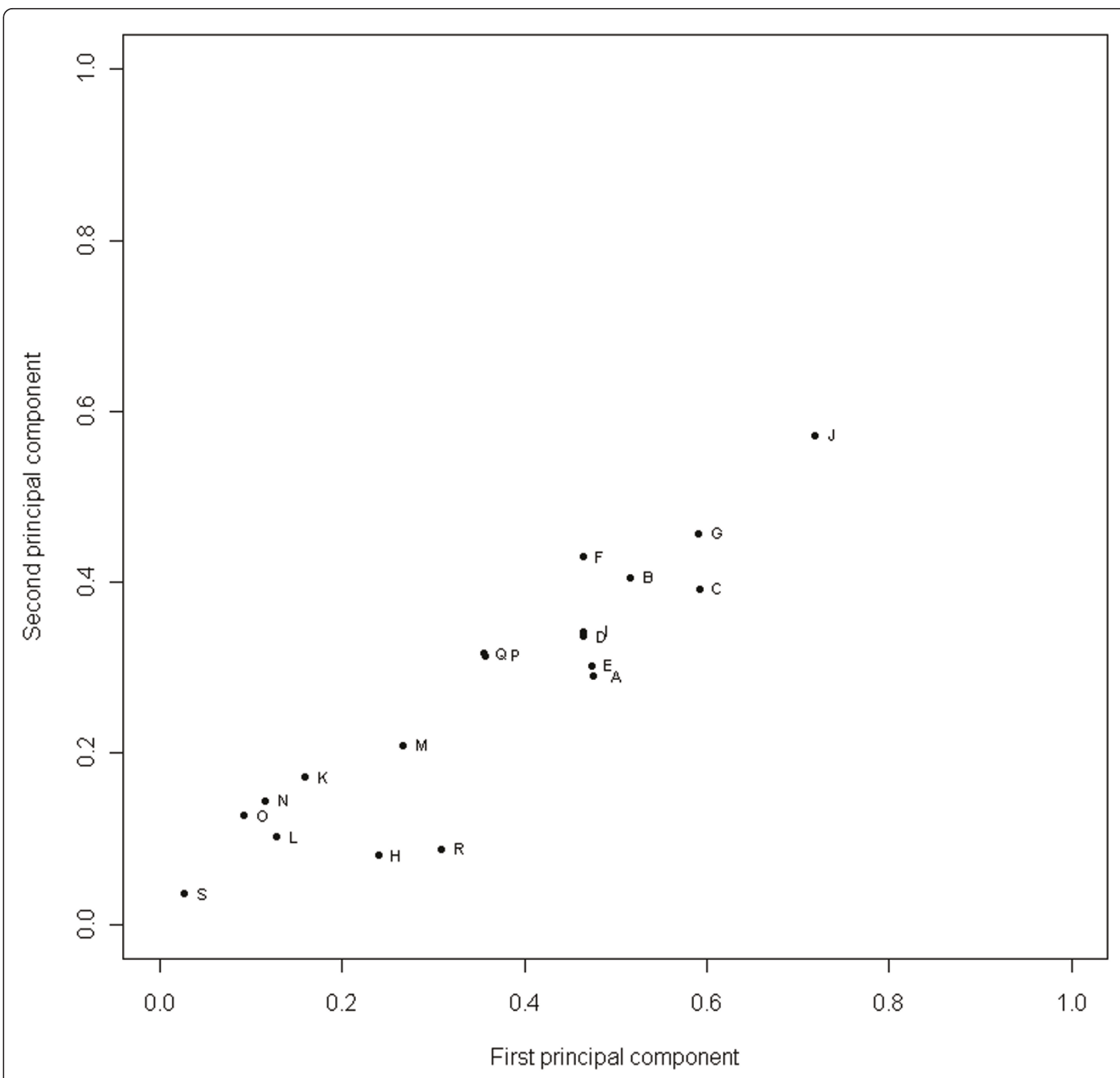

Figure 1 Correlations' graph between variables and the first and second principal components. Total percentage of the variability explained by first and second principal components was 13.6\%. Variables almost uncorrelated with first and second principal components aren't represented on the graph, except subset variable (S). The variables: $B, C, F, G, J$ contributed more to first and second principal components than others. - J: Respondent's intention to recommend A(H1N1) pandemic vaccine to their patients - G: "Belief that A(H1N1) vaccine will be effective" - F: "Belief that $A(H 1 N 1)$ vaccine will be safe" - C: "Belief that $A(H 1 N 1)$ pandemic influenza is a serious disease" - B: "Belief that seasonal influenza vaccines are very useful to protect children health" All variables, including variables almost uncorrelated with first and second principal

component, are listed in an additional file (see Additional File 1).

paediatricians to severe cases of $\mathrm{A}(\mathrm{H} 1 \mathrm{~N} 1)$ disease, as observed in our results, may also have enhanced paediatricians' acceptability of $\mathrm{A}(\mathrm{H} 1 \mathrm{~N} 1)$ pandemic vaccine.

In logistic regression analysis, paediatricians' intention to get vaccinated against $\mathrm{A}(\mathrm{H} 1 \mathrm{~N} 1)$ pandemic influenza themselves was the most significant factor associated with the intention to recommend $\mathrm{A}(\mathrm{H} 1 \mathrm{~N} 1)$ pandemic vaccine to patients. Results obtained by the multiple correspondence analysis (MCA) are consistent with results from the logistic regression analysis. The negative levels were also more discriminatory than the positive ones. This is consistent with results of previous studies that have shown that knowledge and behaviors regarding seasonal influenza influenced $A(H 1 N 1)$ vaccination status: individuals who were not vaccinated against seasonal influenza were less likely to have the 
intention to receive the pandemic vaccine $[37,38]$. Intention to be vaccinated against $\mathrm{A}(\mathrm{H} 1 \mathrm{~N} 1)$ pandemic influenza was also higher than vaccine uptake against seasonal influenza among healthcare workers usually reported in Canadian studies [39,40], which was estimated at $64 \%$ in 2006 [41]. In our study, a significant proportion of paediatricians who disagreed with the usefulness to protect children with the seasonal influenza vaccine did not intended to recommend the $\mathrm{A}(\mathrm{H} 1 \mathrm{~N} 1)$ vaccine to their patients. However, results obtained by MCA should be interpreted with precautions as only $13.6 \%$ of the variability is summarized by the first and second principal components. This is principally due to the uneven distribution of response levels.

Our study has several limitations. First, the study wasn't initially designed for a "before-after" analysis. The increase in the willingness to be vaccinated against $\mathrm{A}$ (H1N1) pandemic influenza observed among paediatricians may result from a response bias of respondents having more doubts about pandemic vaccination before the vaccination campaign actually started. Nonetheless, respondents' demographic and professionals characteristics as well as their attitudes toward vaccination in general were very similar, thus suggesting the two subsets of participants were comparable. Second, the dichotomization of the dependant variable ("strongly agree" and "agree" versus all others) was a conservative choice and physicians who answered "somewhat agree" were considered as having a neutral opinion, not a positive one. Third, the repartition of the answers to the dependant variable in the subset of data collected after the beginning of the vaccination campaign did not allow us to perform two multivariate analysis for the two subset. However, the model was adjusted to take into consideration the time period when the paediatricians completed the survey (before or after the initiation of the campaign). Finally, the response rate was $50 \%$ and a non-participation bias cannot be excluded. However, the response rate remains satisfactory for a mail-based survey with physicians [42-44]. In addition, socio-demographic characteristics of respondents are comparable to those reported in other surveys conducted among Canadian paediatricians $[42,45]$. Socio-professional characteristics of respondents also allow us to suppose a good representativeness.

Results of this study indicated a high level of paediatricians willingness to be vaccinated against $\mathrm{A}(\mathrm{H} 1 \mathrm{~N} 1)$ and to recommend the vaccine to their patients. Lack of knowledge on $\mathrm{A}(\mathrm{H} 1 \mathrm{~N} 1)$ vaccine, belief that $\mathrm{A}(\mathrm{H} 1 \mathrm{~N} 1)$ was not a severe disease as well as concerns over $\mathrm{A}$ (H1N1) vaccine safety and usefulness were barriers to paediatricians' intention to recommend it. This is consistent with barriers to seasonal influenza vaccination among healthcare workers reported in the literature
$[31,46,47]$. Public health interventions to promote seasonal influenza vaccination among healthcare workers should include the delivery of evidence-based information regarding influenza vaccines' safety, efficacy and usefulness. Educational campaigns should also stress out the threat posed by seasonal influenza to healthcare workers and the patients.

\section{Conclusion}

In summary, the results show the important increases in physicians' level of confidence about $\mathrm{A}(\mathrm{H} 1 \mathrm{~N} 1)$ vaccine safety and immunogenicity and their willingness to recommend this vaccine during the first months of the campaign. More than $40 \%$ of all Canadians aged 12 years or older received at least one dose of the $\mathrm{A}(\mathrm{H} 1 \mathrm{~N} 1)$ vaccine during the vaccination campaign [48]. In the province of Quebec, Canada, almost $80 \%$ of the children aged between 6 months and 5 years were vaccinated against A(H1N1) influenza [49]. Paediatricians' support of the vaccination campaign and their recommendations were surely one of the key components of such a success.

\section{Acknowledgements}

We thank all participants as well as the Canadian Association for Immunization Research and Evaluation (CAIRE) and the Canadian Paediatric Society for their collaboration in this study.

\section{Author details}

${ }^{1}$ Institut National de Santé publique du Québec, 2400 d'Estimauville, Québec, Canada. ${ }^{2}$ Centre de recherche du CHUL-CHUQ, Centre Hospitalier de I'Université Laval, 2705 Blv Laurier, Québec, Canada. ${ }^{3}$ University of British Columbia, 229 West mall, Vancouver, British Columbia, Canada. ${ }^{4}$ Canadian Center for Vaccinology, Health Centre, Clinical Trials Research Center, 5850/ 5980 University avenue, Halifax, Nova Scotia, Canada. ${ }^{5}$ Kingston, Frontenac and Lennox \& Addington Public health Unit, 221 Portsmouth avenue, Kingston, Ontario, Canada.

\section{Authors' contributions}

All authors except FD have been involved in the design of the study. ED and FD have drafted the manuscript. FD performed the statistical analysis All authors have read and approved the final version of the manuscript.

\section{Competing interests}

This study was financially supported by the Quebec Ministry of Health and Social Services and by an unrestricted grant from GlaxoSmithKline. No private company or their employees were involved in study protocol/ questionnaire designing, data collection, data analysis and interpretation or manuscript writing.

Received: 6 October 2010 Accepted: 22 February 2011

Published: 22 February 2011

\section{References}

1. Chan M: World now at the start of 2009 influenza pandemic 2009 [http://www. who.int/mediacentre/news/statements/2009/h1n1_pandemic_phase6_ 20090611/en/index.html], 2009-06-11 [cited 2009-10-26].

2. Greenberg J, Fox W: H1N1: media and message. Globe and Mail 2009 [http://www.theglobeandmail.com/news/opinions/h1n1-media-andmessage/article1361395/], accessed October 42010.

3. Wordpress.com: Forget H1N1, The Real Pandemic is Hysterical Media Coverage. 2009 [http://mediacoachblog.wordpress.com/2009/11/08/forget-h1n1the-real-pandemic-is-hysterical-media-coverage/], accessed October 42010. 
4. Blackwell T: H1N1 flu nears peak, experts suggest. The Vancouver Sun 2009 [http://www.vancouversun.com/health/h1n1/H1N1+nears+peak +experts+suggest/2193765/story.html], accessed October 42010.

5. Fitzpatrick M: Brace for more H1N1 deaths, Canada's top doctor warns. The Vancouver Sun 2009 [http://www.vancouversun.com/health/h1n1/Brace +more+H1N1+deaths+Canada+doctor+warns/2188377/story.html], accessed October 42010

6. Mclnnes G: Universal H1N1 vaccine a waste, expert argues. The Vancouver Sun 2009 [http://www.canada.com/vancouversun/news/westcoastnews/story. html?id=58052282-f095-45f7-b109-5c7acffc6581], accessed October 42010.

7. Helferty M, et al: Canadian pandemic H1N1 2009 cases: a description of the changing epidemiology of hospitalizations and deaths in the first and second waves. CMAJ

8. GlaxoSmithKline: AREPANRIX ${ }^{\mathrm{TM}}$ H1N1 AS03-Adjuvanted H1N1 Pandemic Influenza Vaccine. Product information Leaflet [http://www.gsk.ca/english/ docs-pdf/Arepanrix_PIL_CAPA01v01.pdf], accessed 2010 October 4.

9. Ritvo $P$, et al: A Canadian national survey of attitudes and knowledge regarding preventive vaccines. J Immune Based Ther Vaccines 2003, 1(1):3

10. Ritvo P, et al: Vaccines in the public eye. Nature medicine supplement 2005, 11(4):S20-S24

11. Lagarde F: Summary of Public Opinion on Immunization in Canada. Public Health Agency of Canada; 2005, 19

12. Taylor JA, et al: The influence of provider behavior, parental characteristics, and a public policy initiative on the immunization status of children followed by private pediatricians: A study from pedicatric research in office setting. Pediatrics 1997, 99(2):209-215.

13. Schmitt $\mathrm{HJ}$, et al: How to optimise the coverage rate of infant and adult immunisations in Europe. BMC Med 2007, 5:11.

14. Dube $E_{\text {, et }}$ al: Canadian family physicians and paediatricians knowledge, attitudes and practices regarding $\mathrm{A}(\mathrm{H} 1 \mathrm{~N} 1)$ pandemic vaccine. $B M C$ Res Notes 2010, 3(1):102

15. Lavergne B, Frappier-Davignon L: Essai clinique de trivirix (R) pour l'immunisation contre la rougeole, les oreillons et la rubéole. RHMC 1986, 12(19):85-88.

16. Erickson LJ, De Wals $P$, Farand $L$ : An analytical framework for immunization programs in Canada. Vaccine 2005, 23(19):2470-6.

17. Torun SD, Torun F: Vaccination against pandemic influenza A/H1N1 among healthcare workers and reasons for refusing vaccination in Istanbul in last pandemic alert phase. Vaccine 2010, 28(35):5703-10.

18. Pareek $M$, et al: Willingness of healthcare workers to accept voluntary stockpiled H5N1 vaccine in advance of pandemic activity. Vaccine 2009, 27(8):1242-7.

19. Hotelling $\mathrm{H}$ : Analysis of a complex of statistical variables into principal components. Journal of Educational Psychology 1933, 24:417-441.

20. R Development Core Team: R: A language and environment for statistical computing. R Foundation for Statistical Computing. 2005 [http://www.Rproject.org], accessed October 42010.

21. Husson F, Josse J, Lê S: FactoMineR: An R Package for Multivariate Analysis. Journal of Statistical Software 2008, 25(1):1-18.

22. Schwarzinger $M$, et al: Positive attitudes of French general practitioners towards A/H1N1 influenza-pandemic vaccination: a missed opportunity to increase vaccination uptakes in the general public? Vaccine 2010, 28(15):2743-8.

23. Seale H, Leask J, Po K, Maclntyre CR: "Will they just pack up and leave?" attitudes and intended behaviour of hospital health care workers during an influenza pandemic. BMC Health Services Research 2009, 9(30).

24. Chor JSY, Ngai KLL, Goggins WB, Wong MCS, Wong SYS, Lee N, Leung TF, Rainer TH, Griffiths S, Chan PKS: Willingness of Hong Kong healthcare workers ot accept pre-pandemic influenza vaccination at different WHO alert levels: two questionnaire surveys. BMJ 2009, 339(b3391).

25. Esteves-Jaramillo $A$, et al: Acceptance of a vaccine against novel influenza A ( $\mathrm{H} 1 \mathrm{~N} 1)$ virus among health care workers in two major cities in Mexico. Arch Med Res 2009, 40(8):705-11.

26. Lautenbach $\mathrm{E}$, et al: Initial response of health care institutions to emergence of $\mathrm{H} 1 \mathrm{~N} 1$ influenza: experiences, obstacles, and perceived future needs. Clin Infect Dis 2010, 50(4):523-7.

27. Public health agency of Canada: Guidance Document on the Use of Pandemic Influenza A (H1N1) 2009 Inactivated Monovalent Vaccine. 2009, 32.

28. Rasmussen SA, et al: Pandemic influenza and pregnant women: summary of a meeting of experts. Am J Public Health 2009, 99(Suppl 2):S248-54.

29. Canadian Paediatric Society: Resources for health professionals on Pandemic H1N1 2009 influenza ("swine flu") [En ligne] 2010 [http://www.
cps.ca/english/H1N1_Resources.htm], cited 2010 Page consultée le 4 août 2010.

30. Clark SJ, Cowan AE, Wortley PM: Influenza vaccination attitudes and practices among US registered nurses. Am J Infect Control 2009, 37(7):551-6.

31. Hollmeyer $\mathrm{HG}$, et al: Influenza vaccination of health care workers in hospitals-a review of studies on attitudes and predictors. Vaccine 2009, 27(30):3935-44.

32. Posfay-Barbe KM, et al: How do physicians immunize their own children ? Differences among pediatricians and nonpediatricians. Pediatrics 2005, 116:623-633.

33. Szilagyi PG, et al: Immunization pratices of pediatricians and family physicians in the United States. Pediatrics 1994, 94(4):517-523.

34. Katz-Sidlow RJ, Sidlow R: A look at the pediatrician as parent: experiences with the introduction of varicella vaccines. Clin Pediatr (Phila) 2003, 42(7):635-640.

35. Nichol KL, Zimmerman R: Generalist and subspecialist physicians' knowledge, attitudes, and practices regarding influenza and pneumococcal vaccinations for elderly and other high-risk patients: a nationwide survey. Arch Intern Med 2001, 161(22):2702-8.

36. Public Health Agency of Canada: H1N1 Flu Virus - Vaccine Surveillance Report - Adverse Events following Immunization. Weekly Vaccine Surveillance Report; 2010 [http://www.phac-aspc.gc.ca/alert-alerte/h1n1/ vacc/addeve-eng.php], accessed October 42010.

37. Zijtregtop EA, et al: Which factors are important in adults' uptake of a (pre)pandemic influenza vaccine? Vaccine 2009, 28(1):207-27.

38. Maurer J, et al: Does receipt of seasonal influenza vaccine predict intention to receive novel $\mathrm{H} 1 \mathrm{~N} 1$ vaccine: evidence from a nationally representative survey of U.S. adults. Vaccine 2009, 27(42):5732-4

39. Stevenson CG, et al: Prevention of influenza and pneumococcal pneumonia in Canadian long-term care facilities: How are we doing? Can Med Ass J 2001, 164(10):1413-1419.

40. Saluja I, Theakston KD, Kaczorowski J: Influenza vaccination rate among emergency department personnel: a survey of four teaching hospitals. Cjem 2005, 7(1):17-21.

41. Public Health Agency of Canada: Canadian Adult National Immunization Coverage (Adult NICS) Survey - 2006. Public Health Agency of Canada Ottawa; 2006, 92.

42. Duval B, et al: Vaccination against human papillomavirus: $A$ baseline survey of Canadian clinicians' knowledge, attitudes and beliefs. Vaccine 2007, 25(45):7841-7.

43. Duval B, et al: General practitioners' knowledge and attitudes about cervical cancer screening and HPV vaccination. Poster presentation, 24th International Papillomavirus Conference and Clinical Workshop, Beijing International Convention Center. China; 2007

44. Broder KR, et al: Who's calling the shots? Pediatricians' adherence to the 2001-2003 pneumococcal conjugate vaccine-shortage recommendations. Pediatrics 2005, 115(6):1479-87.

45. Victor JC, Brewster JM, Ferrence R, Ashley MJ, Cohen JE, Selby P: Tobaccorelated medical education and physician interventions with parents who smoke: Survey of Canadian family physicians and pediatricians. Canadian Family Physician 2010, 56(2):157-163.

46. Hofmann $F$, et al: Influenza vaccination of healthcare workers: a literature review of attitudes and beliefs. Infection 2006, 34(3):142-7.

47. Zhang J, While AE, Norman IJ: Knowledge and attitudes regarding influenza vaccination among nurses: a research review. Vaccine 2010, 28(44):7207-14.

48. Statistiques Canada: Enquête sur la santé dans les collectivités canadiennes: vaccination contre la grippe H1N1 [En ligne] 2010 [http://www.statcan.gc.ca/ daily-quotidien/100719/dq100719b-fra.htm], cited 2010 Page consultée le 22 juillet 2010

49. Ministère de la Santé et des Services sociaux: L'activité grippale demeure stable alors que les détections du virus respiratoire syncytial sont encore nombreuses au Québec. Flash Influenza 2010, 14(12):1-8.

\section{Pre-publication history}

The pre-publication history for this paper can be accessed here: http://www.biomedcentral.com/1471-2458/11/128/prepub

\section{doi:10.1186/1471-2458-11-128}

Cite this article as: Dubé et al:: $\mathrm{A}(\mathrm{H} 1 \mathrm{~N} 1)$ pandemic influenza and its prevention by vaccination: Paediatricians' opinions before and after the beginning of the vaccination campaign. BMC Public Health 2011 11:128. 